\title{
MACACOS QUE MORD(R)EM
}

\author{
Para meu amigo \\ Franklin Leopoldo e Silva
}

Valentim Facioli*

\begin{abstract}
RESUMO: O ensaio analisa o conto "Macacos" de Clarice Lispector, sob o ângulo da autorreflexividade e negatividade da escritura, tornada antiliterária e investiga a presença do tema da mercadoria moderna e suas repercussōes no estatuto da representação e na consciência alienada da personagem narradora. Analisa ainda a estrutura virtualmente fabular do texto e suas relaçōes com a sociedade brasileira.
\end{abstract}

Palavras-chave: Clarice Lispector, escritura, autorreflexividade, negatividade, mercadoria, alienação, fábula, modemizaçāo.

"Macacos" é um texto que integra o volume A Legião Estrangeira (1964), mais tarde reproduzido numa antologia organizada pela autora, A Imitação da Rosa (1973). À evidência, trata-se de conto que gozava de alguma predileção de Clarice Lispector e, salvo engano, não foi ainda analisado e só pude descobrir brevissimas referências a ele nos estudos que se ocupam de sua obra.

O conto parece estruturado em "duas partes" que guardam entre si relaçōes de simetria e tensāo, que se determinam mutuamente, se entrechocam para constituir a unidade da narrativa. A primeira parte é a anedota do mico macho, com "potencialidades tremendas" que o fazem "gorila" e "homem" ao mesmo tempo. A segunda é a história de Lisette, fêmea, de "extrema doçura" "mu-

(*) Professor do Departamento de Letras Clássicas e Vernáculas, FFLCH/USP. 
lher” De fato, as oposições sāo bastante evidentes, mas o que ressalta é que para a voz narradora - uma mulher, mãe de dois filhos em primeira pessoa, nem o mico macho nem a fêmea têm identidade estável, ambos sāo menos o que são e mais o que parecem ser ao olhar perturbado que os vê, imagens deformadas da sensibilidade que os percebe e os transforma peculiarmente, através de recursos comparativos, metafóricos e mitificantes. Os micos são ao mesmo tempo "humanizados" e "bestializados". como seres que transitassem de uma condiçāo a outra, feitos fetiches vivos ante o olhar que os observa e narra.

Há uma espécie de contraponto entre a história de Lisette e a do mico macho, como tensāo organizadora da busca de sentido desses seres instáveis, tornando instável o próprio tema/assunto do conto, de vez que ele se configura ao final não propriamente como histórias de micos, senāo como um croqui breve do percurso da subjetividade contraditória da narradora em suas relaçōes tensas com os mesmos bichos e também com os filhos, com o homem, com o mundo e consigo mesma.

Vejamos como se dá esse percurso na "primeira parte" do conto. Quando chega à casa da narradora, o mico macho sem nome, em forma de presente, ela está vivendo problemas de seu cotidiano pequeno-burguês : o Ano Novo, a falta de água, de empregada, "fila para carne" e "o calor (que) rebentara". Logo, o mico macho torna-se um dado a mais de perturbaçāo da rotina, que a narradora, entretanto, nāo sente apenas como tal. $\mathrm{O}$ animalzinho logo se constitui numa sombra opressiva (que também parece ter produzido ou precipitado a consciência dos transtornos "usuais"), presentificação abrupta de uma outra relação, que é sugerida mas nāo assoma plenamente à superficie: a relação da narradora com o homem (ausente/presente). Em tese um marido, cujo silêncio textual, contudo, sugere os homens ou os machos em geral. O comportamento e a aparência do mico macho só lembram à narradora essa sombra opressiva e invasiva, com a qual ela estabelece de pronto, na sua solidāo, uma relação de recusa, de distância e mesmo de rejeição completa, ainda que pudesse tornar-se "responsável pelo seu destino, já que ele próprio não aceitava culpas" Essa presença desperta nela sentimentos que pareciam adormecidos no silêncio do recalque e que nāo são quaisquer uns, mas sentimentos arquetipicos da relação AMOR E MORTE : "uma 
amiga entendeu de que amargura era feita a minha aceitação, de que crimes se alimentava meu ar sonhador"

O fato é que pela mão da amiga e de "uns meninos de morro" a narradora, ao livrar-se do mico, cometeu o crime, resultando-lhe, com ele e sua culpa, no "desvitalizado Ano Novo", o triunfo de uma perda, uma vitória fracassada, por paradoxo, pois nessa ocasiāo "pelo menos ganhei uma casa sem macaco" Mas a vitória desse crime, dessa ausência, desse recalque reposto e desse silêncio é a instauração de um vazio que amplia a solidāo, quase tornada desamparo, revelando a solidāo culpada de um gesto inteiramente egoísta, revestido com a máscara do alivio. $O$ ganho/perda da narradora foi a perda certa para os filhos. Seu alivio é a contraface da tristeza dos meninos, aquele explícito mas esta apenas latente na narrativa. A narradora estilhaçada pela sombra opressiva do outro, o mico macho, "gorila" "homem" não se pode reconstruir de seu abalo através de um retorno puro e simples ao cotidiano pequeno-burguês, este, agora, invadido e turvado pela angústia contraditória do fracasso no alívio e na vitória da "casa sem macaco"

Esse efeito se torna decisivo porque inclui na sua relaçāo vitoriosa com o mico macho um outro ser: o menino menor. A diferença mediadora é que para o menino o mico não é problemático, nāo configura a relação sombria que perpassa a mãe. $\mathrm{E}$ mais: o menino percebe antes que a mãe, num plano intuitivo e simbólico, a natureza conflituosa da relação que ela estabelece com o mico. O menino, por assim dizer, intui o conjunto complexo e tenso que envolve a māe, o mico e o homem ausente/ presente e o configura como "catástrofe iminente". jogando agora com a oposição, complementar à outra, invertida em seus mesmos arquétipos, MORTE-AMOR

"Meu menino menor sabia, antes de eu saber, que eu me desfaria do gorila: 'E se eu prometer que um dia o macaco vai adoecer e morrer, você deixa ele ficar? e se você soubesse que de qualquer jeito ele um dia vai cair dajanela e morrer lá embaixo?' Meus sentimentos desviavam o olhar".

Menino menor e macaco (não importa se macho ou fêmea) como que se identificam na mesma espontaneidade e alegria sem 

p. 253-266, 1997.

culpa, alheios à perturbação opressiva da mãe, embora o menino intua o perigo da morte simbólica (pela expulsão e ausência) que pesa sobre o animal. Por isso parece-lhe possivel que a morte real, o perigo dela ou sua ameaça, pudesse sobrepor-se à outra, compensála ou cancelá-la. Mas nāo. O crime da māe narradora é premeditado, inevitável e também, ao final, irremissivel. Diante do mico macho a mãe não pode ter a espontaneidade e a alegria sem culpa do filho menor, de fato, nem compreendè-las, nem aceitá-las. Para ela, livrar-se do macaquinho é livrar-se do destino dele e reconstruir um silêncio pela ausência, repor o recalque que tenta ocultar o conflito com o homem (mico/gorila, macacão pequeno), ainda que à custa da alegria do filho. Isso vale o crime, conquanto a culpa o antecedesse, pois que latejava no recalque, cuja causa a narradora ignora e transfere para o mico, não pelo que este era, mas pelas imagens que seus olhos viam nele. Por um mecanismo de transferência, que é psicológico e também social, a mãe recolhe a sombra opressiva que the traz o mico e a atira sobre o filho menor; alivio dela e carência de alegria dele. Assim, para se livrar da opressão a mãe narradora torna-se opressora e impõe a morte (da alegria do filho e do mico, pela supressão, ausência e silêncio de ambos), realimentando o recalque e impondo sua condição hierarquicamente superior de mãe e narradora, tornando a positividade de seu alívio uma negatividade, inerentes ambas ao mesmo processo : "a casa sem macaco"

Assim, a narradora ganha esse fetichizado presente naquele "Ano Novo desvitalizado" (com essa surpreendente mas significativa adjetivação...) que é a morte da vitalidade do mico e do menino, ou seja, a morte do sentimento autêntico da espontaneidade e da alegria sem culpa. A narradora quis que esse abafamento do outro (mico, menino, homem, gorila) fosse a possibilidade de recompor sua paz alienada de pequeno-burguesa anterior à chegada do estranho perturbador. Mas performa-se na consciência da narradora uma culpa duplicada: a da presença e a da ausência do outro; não é possivel ficar com ele e já também nem sem ele. E não apenas pela narradora em si mesma, senāo porque o filho é parte dela, constitui essência de seu ser de mãe e pequeno-bur- 
guesa, duplicando-se o filho na sombra do homem ausente/presente e do mico macho, exigindo dela a morte simbólica deles todos. Assim, ao livrar-se do mico, ela se livrou do homem e também da essência incômoda do menino, isto é, de sua alegria sem culpa. Mas a mãe narradora não está livre e sim contaminada da culpa de seu crime.

Algo vivo permaneceu nela sob a cinza quente da supressão, do recalque e do silêncio: um vago sentimento de uma identidade possivel com a vitalidade, a espontaneidade e a alegria sem culpa do Outro, (o mico macho e o menino menor). Por isso, só quando a mãe narradora, um ano depois, "acabava de ter uma alegria" desperta de novo para o problema. E agora a alegria assoma com suas virtualidades humanizantes e vitalizantes, o que the permite romper a solidão através da solidariedade:

"imaginei uma cadeia de alegria: 'Guem receber esta, que a passe a outro'. e outro para outro, como o frêmito dum rastro de pólvora. E ali mesmo comprei a que se chamaria Lisette".

Há um aspecto a ser notado, agora: o mico macho chegou à casa da narradora como um presente, cuja origem não é explicada e logo torna-se problema, que ela pretende seja um problema de toda a família, pois o expressa através do pronome nós, o qual, aliás, logo desaparece, substituído por eu. Trata-se de algo perturbador, indesejado e invasivo. Já Lisette é comprada, num gesto consciente de reposição da perda, uma açāo consciente nascida de "projeto" de intenção. A distância entre ganhar e comprar aplicada aos dois macaquinhos é relevante, como veremos adiante.

Lisette é adquirida em forma/aparência já humanizada, inclusive tem nome : "Tinha saia, brincos, colar e pulseira de baiana" $\mathrm{E}$ ainda tinha "um ar de imigrante que (...) desembarca com o traje típico de sua terra. De imigrante também eram os olhos redondos" "era mulher em miniatura" (...) Era de uma tal delicadeza de ossos. De uma tal extrema doçura. Mais que os olhos, o olhar era arredondado" Os gestos, a postura, os modos de comer, de fazer raros cari- 

p. 253-266, 1997.

nhos, tudo nela era humano, e especialmente feminino. O nome de Lisette, de gente, signo estranhado e dignificado pelo duplo $t$, a sugerir um francesismo, impōe uma ambiguidade, digamos, insolúvel, no nivel expresso da própria narrativa. Primeiramente, não se sabe com precisão quem deu esse nome, pois a construção verbal que o designa, permite ler sentidos diferentes : " $\mathrm{E}$ ali mesmo comprei a que se chamaria Lisette" Não se sabe se a macaquinha já tinha o nome e a narradora só o soube após a compra, ou se alguém, ela mesma ou seus filhos the deram o nome que ela ainda não tinha. Mas nomear o bicho com nome humano é ao mesmo tempo humanizar o animal e bestializar o homem ou, se quisermos, no plano mítico e arquetípico, essa nomeação é a identificação do homem com seu totem, tomando-o como extensão de si mesmo e seu protetor, tanto quanto do clã.

Pode-se ainda assinalar, sumariamente, que a nomeação também implica a posse e o dominio sobre o outro, não mais, ou não só, na relação totêmica, senão que numa relação fetichizada de mercadoria, na qual se perdeu a memória do totem. Parece haver também ironia, pois Lisette, como nome afrancesado, sugere um "traço cultural" de classe média, supostamente requintada, dada a certos cacoetes, inclusive linguisticos, de supor a coisa estrangeira, ou com aparência ou nome de estrangeiro, mais bonita e aristocrática. De todo modo, o nome de Lisette aplicado à macaca imigrante, vestida de baiana, funciona como um "disparate irônico"

$\mathrm{Na}$ "segunda parte" a narrativa destaca em Lisette certos traços que a narradora considera adequadamente femininos, por oposição e contraponto aos masculinos do primeiro mico: extrema doçura, olhar arredondado, os enfeites em ordem e os gestos a sugerirem pudor, carinhos e suavidade; em suma, predisposição para o amor, a qual contamina a própria família. " Olhando-a, percebi então até que ponto de amor já tínhamos ido” Esse amor da familia por Lisette, contudo, é também forte sentimento de posse, de propriedade : "estávamos na área de serviço admirando Lisette e o modo como ela era nossa” Parece ser nessa fusão de sentimento de amor e propriedade, ou, de amor como propriedade, que algumas caracteristicas femininas da macaca, atribuidas pela 
narradora, de repente, se transformam em signos de morte. Morte certa e irrevogável, porém antecedida de "um sopro de vida" trazido pelo oxigênio que, por efeito interno, revelou uma Lisette mais que macaca, humana-mulher: De olhos muito menos redondos, mais secretos, mais aos risos e na cara prognata e ordinária uma certa altivez irônica. $\mathrm{O}$ oxigênio enquanto metáfora reveladora de uma verdade essencial e comum de Lisette e da mulher: um pouco mais de oxigênio, e deu-lhe uma vontade de falar que ela mal aguentava ser macaca; era, e muito teria a contar.

A súbita irrupção desse discurso indireto livre parece o ponto de maior aproximação entre a narradora e Lisette. Mas o fato é que, de novo, a catástrofe iminente, reposta no "jogo" morte- amor, agora revela a narradora "transformada" pois disposta a qualquer sacrificio para salvar a Outra, talvez salvar no fundo a si mesma, como identidade feminina em vias de constituir-se: dar a macaca ao enfermeiro no caso de este salvá-la. O enfermeiro, entretanto, parece amar Lisette sem o sentimento de propriedade e por isso tem um gesto compreensivo e humanizado: Se eu curar Lisette, ela é sua, responde ele. Vê-se, entretanto, que mesmo o empenho de todos já não é mais suficiente para salvá-la, talvez porque amada como propriedade a fêmea não pode ser salva, seja quem for que a ame. Ao mesmo tempo, a fala do enfermeiro, repassada de fundo edificante, é tratada pela narradora com ironia amarga, porque insinuava ou sugeria certas "garantias" ou possibilidades que ela, narradora, percebe não existirem nem para a vida nem para o amor.

O último parágrafo, clímax com tom de anticlimax, cifra novas astúcias ao enigma, sob a aparência de o estar decifrando, deixando-o como se fosse uma estrutura de consolação ou alivio, e ironizando assim implicitamente a relação texto-leitor, como se mandasse este último "pentear macacos"... :

"No dia seguinte telefonaram, e eu avisei aos meninos que Lisette morrera. O menor me perguntou: 'Vocè acha que ela morreu de brincos ?' Eu disse que sim. Uma semana depois o mais velho me disse : 'Você parece tanto com Lisette!' 'Eu também gosto de vocè', respondi “ 

p. 253-266, 1997.

Somos informados que para os meninos a mãe "sobrou viva" como simulacro de Lisette, parecida com ela, a condição feminina identificada no "morrer de brincos" percepção que a narradora também parece ter de si própria ao responder ao filho com a frase banal, meio que obrigação materna. Mas a condição de simulacro estava dada desde o começo, sendo o "marido" ou o "homem" ausentes do texto, percebidos como tal no mico macho, tendo a narradora, portadora do poder de narrar, só tardiamente e através dos meninos, percebido sua própria condição de simulacro do mico fêmea. Pode-se assinalar, entretanto, essa inversāo como uma progressão no processo, pois a principio o mico macho parece ser o simulacro do homem ausente, tanto quanto Lisette o seria da mãe. Mas os meninos percebem o outro lado e ensinam à mãe narradora, à narrativa e ao leitor, que a mulher e o homem é que são simulacros dos micos, pois estes preexistem àqueles, sendo os micos portadores de uma "verdade" (ou uma "identidade") primeira, originária, nuclear, a qual, nos humanos, machos ou fêmeas, é apenas uma imitação daquela. Digamos, numa frase meio clariceana: o outro é mais eu do que eu mesmo.

Do mesmo modo, essa revelação insinua a própria natureza da narrativa, representação como simulacro, que sonda a origem de seu ser e de sua matéria, pondo-se a princípio como a própria realidade ou a verdade, para depois "sobrar" apenas enquanto simulaçāo, que, ao reconhecer-se isso, carrega o ônus da própria morte por pretender sobrepor-se à vida e à verdade desta. Assim, a narrativa que pretendia de inicio representar os macacos como simulacros, por sua pretensão fraudulenta, denuncia-se ela própria como um simulacro e por isso merece a rejeição e a morte, ainda que portadora de alegrias e sustentável por algum oxigênio extra. Ao mesmo tempo, esse fracasso é sua vitória, de vez que ao denunciar-se como simulacro e pretender sobrepor-se à vida e à verdade ela é capaz, em cada "sopro de vida" de tornar-se diferente sendo a mesma e de repor-se infinitamente como simulacro que reconhece sua natureza fraudulenta. Essa é a instância da negatividade da literatura antiliterária do texto, podendo-se arriscar, talvez sem exagerar a potencialidade dele e de Clarice 
Lispector, a hipótese de que sem essa negatividade autocrítica a narrativa não transporia as barreiras das aparências do mundo e se faria simulacro inconsciente, assumindo sua sagraçāo em mercadoria e realizando-se como verdade em si mesma.

O estranho opressivo do mico macho, a alegria dos meninos, o exótico de Lisette e as mesmas angústias e egoismo da mãe são as matérias vivas da narrativa, tanto quanto a exclusão do mico macho e a morte da macaquinha, e obrigam que a narradora se torne "responsável pelo seu destino" isto é, pelo ato de narrar e pela natureza do narrado com implicaçāo fundamental sobre o tipo de pacto que será firmado com o leitor. É evidente que esse pacto se organiza pela negatividade sem consolo e sem alivio, pois revela que as relaçōes humanas, mesmo entre māe e filhos, se fundam na carência, na exclusão e na morte. Ou seja, quando denuncia esse terrivel fracasso humano, a narrativa ganha direito de existir, mas apenas para essa denúncia, negando-se para qualquer outra alternativa, que, se insinuada, aparece como chavão irônico, como a frase final da mãe ao filho, que desarma a confiança, alguma certeza e o bem estar do leitor. Nessa direção de leitura o crime e a culpa serão, necessariamente, integrantes dessa escritura problemática e emblemática, que quer dizer o que não se diz ou não se pode dizer; serāo tema e forma, pois que constituem dimensōes de violência da narrativa contra si mesma e contra qualquer pacto confortável com o leitor, ambos repassados de exclusão e morte.

O conto pode ser lido também como croqui do percurso da subjetividade da narradora, na passagem de uma descoberta que vai da aparência enganosa à essência quase irreconhecivel, da percepção de que o cotidiano alienado da pequeno-burguesa havia rompido a solidariedade com o outro e sua própria identidade de māe estabelecida. O sentimento articulador dessa descoberta e da passagem é a alegria, espôntanea, intuitiva e natural nos micos e nos meninos e mal "reconstruída"como identidade instável e efêmera na mãe narradora. $O$ texto estrutura ainda a condição 

p. 253-266, 1997.

problemática da mulher mediante a revelação do homem ausente, como sombra opressiva, presentificado como recalque que retorna para deformar o olhar. A narradora vê no mico macho essa sombra do homem e em Lisette a projeção de sua própria imagem, deformadas ambas. A solidão da mulher fica evidenciada diante do amor, da morte e do outro, desestruturada sua identidade, fragmentada, estilhaçada sua relação com a alteridade e consigo mesma.

Nesse jogo, o fio vivo que o tece, todavia, é muito menos visivel. É a relação da narradora (e da narrativa) com a mercadoria, relação menos percebida e mais intuída, que fica na sombra, conquanto seja forte. Talvez o enigma decisivo do texto, pois ele encadeia, a meu ver, tanto o ser/estar no mundo da mãe narradora, suas relações com o outro (sejam os micos, os filhos, o homem) quanto o problema da natureza do texto, o estatuto de sua representação e o pacto com o leitor.

De início, os problemas da mãe narradora são os da sua relação dificil com o mundo externo em sua forma mercadoria mais evidente: sem água, sem empregada, fila para a carne. São carências de mercadorias, que o cotidiano de sua condição de classe faz passar como transtornos absurdos e inesperados. Mas o excesso da natureza ("o calor rebentara") também insinua carência de mercadoria, algum objeto ou meio que pudesse atenuá-lo. Assim sociedade e natureza se comunicam para produzir carência, igualando-se num mesmo nivel e operando-se sibilinamente um trânsito ou uma extensāo de uma para outra, iluminando o funcionamento de base da ideologia, ou seja: a naturalização da história, de que a mãe narradora não parece ter consciência, pois ela está aderida, sem distância, a esse discurso pequeno-burguês.

$O$ desdobramento desse núcleo inicial atinge a relação da narradora com os micos e com os filhos. O mico macho é um presente e, paradoxalmente - mas de acordo com a projeçāo da imagem do homem que ela, a măe, nāo tem e recusa - é inaceitável, inconveniente, monstruoso, que chega como invasor e opressor e a quem é preciso matar pela expulsão/exclusāo. Lisette é a realização de uma compra, gesto intencional, afirmativo e ainda solidário, mas que 
resulta em seu efeito oposto. O presente é saudável e odiado; a compra é amada mas marcada de morte. O destino dos dois micos parece relacionado com a forma mercadoria usual embora em posição invertida, o que pode permitir relacionar essa situaçāo com duas coisas: a posição contraditória da narrativa no mercado e um modo peculiar da mulher-māe perceber-se mais vitimada pela mercantilização degradada do que o homem. Digamos, sucintamente, que a relação entre presente e compra, tal como o texto a propōe para a māe narradora e os meninos com os dois macaquinhos, seja a sugestão sibilina das muitas faces da alienação do pequeno-burguês pela mercadoria.

Uma delas parece encenada na suposiçāo "ingênua" da mãe de que seria possivel, com a compra de Lisette, reaver ou restabelecer a alegria dos meninos. Mas aí a compra revela-se um recurso fraudulento, tanto quanto a narrativa, pois dela decorre a fatal ronda da morte de Lisette, mercadoria doente. Nesse caso, mercadoria e alegria autêntica e natural não podem conviver, mesmo quando a māe se identifica com Lisette e seu destino; mercadoria e desejo não se identificam e não se mostra viável a realização deste pela posse daquela. Parece-me que, por essa via, funda-se uma culpa irremissivel, sentida mas não identificada, em dois movimentos contraditórios e complementares: o movimento desejante, que se supōe realizável pela posse do outro, e sua introjeção complexa de desejo de ser desejado, pondo-se assim o ser em disponibilidade para ser possuído pelo outro. Não são movimentos inocentes, senão que pactuam com a forma mercadoria, enquanto o ser humano parece dominar o objeto e não se questiona se está sendo dominado por ele e seu fetiche. Enfim, a crença na própria humanização atravês do fetiche...

O resultado é uma ilusão mortal, uma decepçāo com duas faces: a desilusão legítima e o ato egoista. Esse impasse, de fundo ético, está justamente na percepção da narradora de que ela se deixou dominar por relaçōes que, embora disfarçadas, obedecem aos movimentos de compra e venda, desumanizantes, conquanto resultados das ações e das intençōes (e mesmo das necessidades) humanas. A mãe roída de desumanização só a muito custo reco- 

p. 253-266, 1997.

nhece o outro (os micos, os meninos) quando nāo contaminado pela alienação mercantil. Daí ser-lhe indecifrável e repelente o mico macho, porque associado ao homem já desumanizado; como também ser-lhe estranha a alegria dos meninos diante dos bichos: e, ainda, figurar-lhe exótica e mesmo cômica a pobre Lisette, vestida de baiana, com seus brincos e olhos redondos de migrante, carregada de um carnaval latente. São seres inusitadamente amalucados que não têm lugar na vidinha cheia de contrariedades do pequeno-burguês alienado.

Parte da culpa da mãe decorre desse desencontro e da cegueira que lhe corresponde, que parecem provir sempre de outro e estranho lugar indecifrável e brotar de outros motivos, pois o verdadeiro será sempre ocultado e desviado de foco pelo recalque e a naturalização do efeito dessa história desumana. Assim, os bichos e as crianças, na sua alegria e espontaneidade, virtualmente subumanas porque semiaculturadas, revelam-se, contudo, como verdades primordiais, anteriores e pouco ou nada acessiveis aos homens, tornados meros simulacros das mercadorias que os dominam. $\mathrm{O}$ texto de Clarice Lispector tem sua construção fundada numa poética que exige a sondagem artística como via contraditória de acesso a esse miolo estilhaçado e problemático das relaçōes humanas. Texto que se faz linguagem rompida com mediaçōes também alienantes de gênero literário e da própria noção institucionalizada de literatura, para organizar-se como uma farpa aguda com a qual o leitor tem de se haver, equilibrando-se ou ferindo-se, mas nunca sentando-se confortavelmente.

"Macacos" se estrutura como uma fábula virtual, algo sugerido quando a mãe narradora sente e afirma que Lisette tem um irreprimivel desejo de falar e teria muito a contar. A fabula virtual faz com que os bichos tenham exemplaridade com ressonâncias para os seres humanos, mas eles já não podem falar explicitamente como na fábula tradicional. É reconhecido que a fala fabular tradicional é prôpria de um mundo mágico-mítico ligado à "alienaçāo rústica" de economias pouco desenvovidas e de base rural, quando os homens podiam reconhecer a natureza sem a mediaçāo necessária do mercado. Mas, certamente, nāo era o caso do Rio de Janeiro (Copacabana, anos 60 ...), de cultura urbana, onde 
mesmo os bichos são mercadoria. Não obstante, o Brasil ainda era, como país, meio urbano meio rural, condição sutilmente indicada tanto pela presença mesma de animais agrestes na grande cidade, quanto pelo fato de um mico ser presente e o outro ser compra. Nessa circunstância a fábula tradicional jả não seria "verossimil" mas é possivel retomả-la modificada e com essa reestruturaçāo falar nas entrelinhas o que a escrita não quer explicitar. Ao mesmo tempo, e com ironia derrisória, numa sociedade como a brasileira, os bichos ainda podem revelar algo essencial da condição urbana do nosso homem meio moderno, virtualidades que desmascaram o simulacro em que se vai tornando esse homem, parcialmente mercantilizado. A retomada da estrutura mitica da fábula modificada e "modernizada" é, enquanto forma literária, homóloga à própria forma social brasileira em processo de modernização. Seu interesse está em que bichos e crianças permitem reconhecer identidades perdidas, ou simulá-las, ou fraudá-las mais uma vez, feiçōes ou simulacros, que a eloquência da escrita fundada na negatividade capta problematicamente ao tentar dizer o que não se pode dizer de outro modo, por outros meios, que é talvez indizivel senão por via dessa escrita.

Finalmente, vale lembrar como a macaca Lisette carrega a imagem ancestral da Macabéa de $A$ hora da estrela. Pode-se dizer que é um signo a ser desenvolvido, simulacro ela também de uma intertextualidade então apenas virtual, quase um "ato falho" que ainda esperaria anos para assomar ao centro e à superficie da escritura da autora. Trata-se da pré-constituição de uma alteridade mais radical, que teve de esperar outros percursos da escritora para integralizar-se até às últimas conseqũências.

\section{BIBLIOGRAFIA}

LISPECTOR, Clarice. "Macacos" in A imitaçāo da rosa. Rio de Janeiro, Artenova, 1973.

LUCCHESI, Ivo. Crise e escritura: uma leitura de Clarice Lispector e Vergílio Ferreira Rio de Janeiro, Forense-Universitária, 1987 

p. 253-266, 1997.

MARTINS, Gilberto Figueiredo. As vigas de um heroísmo vago (Três estudos sobre A maçã no escuro). São Paulo, FFLCH/USP, 1996 (Dissertação de Mestrado).

NUNES, Benedito. O drama da linguagem: uma leitura de Clarice Lispector. São Paulo, Ática, 1989.

REVISTA TEMPO BRASILEIRO, 104. Rio de Janeiro, Tempo Brasileiro, 1991. REVISTA TRAVESSIA, 14. Florianópolis, UFSC, 1987.

REVISTA REMATE DE MALES, 9. Campinas, IEL/UNICAMP, 1989.

SANTOS, Roberto Corrēa dos. Lendo Clarice Lispector. $2^{\mathrm{a}}$ ed. Sāo Paulo, Atual, 1987.

WALDMAN, Berta. A paixão segundo C.L. $2^{\text {a }}$ ed. São Paulo, Escuta, 1992.

ABSTRACT: This essay analizes the short-story "Macacos", by Clarice Lispector, from the point-of-view of self-reflexivity and negativity of the writing become anti-literary and investigates the presence of the modern merchandise theme and its reactions in the domain of performance and in the alienable consciousness of the narrator character. It also analizes the virtual fable structure of the text and its relationship with the Brazilian society.

Keywords: Clarice Lispector, writing, self-reflexivity, negativily, commodity, alienation, fable, modemization. 